\title{
O MÉTODO CRÍTICO DE ANTONIO CANDIDO: FORMA, LÍRICA E SOCIEDADE
}

http://dx.doi.org/10.11606/issn.2237-1184.v0i30p82-92

Betina Bischof ${ }^{\mathrm{I}}$

\section{RESUMO}

Este artigo considera a construção do método crítico de Antonio Candido a partir de um ângulo específico e pontual, qual seja, o aproveitamento que ele faz de um ou dois ensaios críticos de Roger Bastide, a cujas premissas (a presença na ausência) dá um impulso e alcance que não se poderia prever, face às hipóteses ainda relativamente incipientes do sociólogo francês, que atuou na USP e foi professor de Candido. Em seu segundo momento, o artigo busca considerar como o método desenvolvido por Candido, que busca o externo (sociedade, história, psicanálise) na própria tessitura da obra literária (em sua forma), trabalha com a especificidade do poema lírico.

\section{ABSTRACT}

This article focuses on the construction of Antonio Candido's critical method from a specific perspective, namely, the use he makes of one or two critical essays by Roger Bastide, a French sociologist who taught at USP and was one of Candido's Professors. Bastide's concept of presence in absence is taken over and developed by Candido, so that it acquires a scope that could not have been predicted, given the relatively tentative nature of Bastide's hypotheses at that time. Additionally, the article examines how the method developed by Candido, which seeks to grasp the external elements (society, history, psychoanalysis) in the very fabric of the literary work (in its form), deals with the specificity of lyric poetry.

\footnotetext{
'Universidade de São Paulo, São Paulo, São Paulo, Brasil.
}

\section{PALAVRAS-CHAVE:}

Antonio Candido; método crítico; poesia; Roger Bastide.

\section{KEYWORDS}

Antonio Candido; critical method; poetry; Roger Bastide. 
A

minha fala neste Seminário ${ }^{1}$ tem dois propósitos: acompanhar um dos caminhos da construção do método crítico de Antonio Candido (a partir do vínculo com um de seus professores). E comentar a utilização desse método (cujos resultados talvez mais consistentes ou conhecidos se encontrem nos estudos da prosa de ficção) também na Lírica.

O título desta fala, como consta no Programa do Seminário, busca a articulação entre poesia, forma e história, na crítica de Antonio Candido. De início, no entanto, não falarei de nenhum desses pontos em específico e também não da obra de A. Candido. Começo recuando uma geração, até os escritos e aulas de um de seus professores, Roger Bastide, que veio ao Brasil em 1938 para lecionar no curso de sociologia da Universidade recém fundada, integrando a assim chamada "missão francesa" na USP.

O âmbito de interesse e atuação de Bastide era já então amplo e cresceu significativamente com o longo período em que passou aqui, abraçando o folclore e a cultura popular; o barroco, as artes visuais e a arquitetura; as relações entre negros e brancos, as religiões africanas; a possessão e o candomblé (PEIXOTO apud BOTELHO; SCHWARCZ, 2009, p. 187). No Brasil, Bastide, longe de fechar o foco em sua especialidade e na bibliografia francesa, lança-se a um projeto de leitura detida e ampla da produção artística e intelectual brasileira, em âmbitos que compreendiam o seu campo de atuação (o ensaísmo histórico-sociológico, os estudos antropológicos), mas também naqueles que iam além dos seus objetos usuais de estudo e pesquisa ${ }^{2}$, como a literatura, as artes e a arquitetura.

"Seus primeiros escritos [lembra outra aluna sua, Gilda de Mello e Souza] já atestam o esforço admirável de compreensão com que se debruça sobre o país que o acolhe, e é tão diferente do seu. Durante os dezessete anos que vive entre nós, procura informar-se exaustivamente sobre a realidade brasileira, através dos viajantes estrangeiros, dos historiadores, dos sociólogos, dos escritores, da arte em geral" (SOUZA, 1980, p. 18), tornando-se, diz por sua vez A. Candido, "um estudioso que pesou de maneira notável na interpretação de fatos, idéias e obras" (CANDIDO, 2004a, p. 108) na vida intelectual, à época.

Candido lembra que a influência de Bastide sobre a geração seguinte foi grande não apenas a partir de sua produção escrita, mas também em decorrência do "contacto direto com amigos e alunos. Eu, pessoalmente [diz ainda Candido, num texto que retoma esse convício, décadas depois], lhe devo muito e às vezes me surpreendo, relendo a anos de distância

1 O Seminário "Antonio Candido e a literatura", promovido pelo Departamento de Teoria Literária e Literatura Comparada da USP, ocorreu em novembro de 2018.

2 Cf. PEIXOTO, Fernanda Arêas, op. cit. p. 186-7. 
algum escrito dele, ao verificar até que ponto certas idéias que julgava minhas são na verdade não apenas devidas à sua influência, mas já expressamente formuladas por ele" (Idem, p. 109). O ponto preciso do interesse de A. Candido pelos ensaios de crítica literária de seu professor está na difícil mescla que propõe, entre dois campos do saber: os ensaios de Bastide, diz ele, "eram de intuito predominantemente literário, mas quase sempre entrava neles a visão sociológica como alicerce teórico ou componente interpretativa, tornando Roger Bastide um dos poucos a usar com segurança e felicidade essa combinação difícil" (p. 109). Se esse é o ponto de interesse, "a maior contribuição de Bastide aos estudos da literatura brasileira" será, ainda de acordo com Candido, o texto "magistral" 3 intitulado "Machado de Assis paisagista".

Bastide escreveu esse artigo em 1940, para responder à crítica da época, segundo a qual, para a surpresa do leitor contemporâneo de Machado de Assis, a ausência de descrições (a ausência de paisagem), nos contos e romances machadianos, implicaria um escritor menos brasileiro, desprovido de cor local. Contrapondo-se à opinião corrente, Bastide defende em seu artigo que a natureza brasileira, em Machado, não deve ser buscada como referência externa, mas sim vista como parte intrínseca (constitutiva) da composição de enredo e personagem. Estudando Machado de Assis, Bastide teria elaborado, diz Candido, uma "espécie de paradoxo metódico, ou estratégico, provando que nele a paisagem está presente com grande força, ao contrário do que sempre se afirmou; só que está na filigrana, tão intimamente entrosada com a caracterização e a condução do enredo, que não fere a atenção do leitor" (p. 114). "Assim, seria possível dizer, como ele [Bastide] nos dizia em aulas e conversas, que Machado de Assis podia até ser considerado 'mais brasileiro' do que, por exemplo, Alencar ou Euclides da Cunha, porque nele a paisagem do Brasil se torna algo essencial à economia profunda da obra, insinua-se no gesto do personagem, na fisionomia, no sentimento, na ação, como uma espécie de presença virtual" (p. 114).

Se essa é a tônica do texto, será interessante acompanhar de mais perto os passos do argumento, lembrando que não existe à época, por parte de Bastide, a clara formulação de um método de leitura do texto literário, ainda que algo do funcionamento do método crítico posteriormente desenvolvido por Candido possa ser reconhecido - em retrospecto, e em condição embrionária - na promissora análise da arquitetura de personagem e enredo, em Machado de Assis, feita por Bastide.

Veja-se a construção do argumento. Em "Machado de Assis paisagista", Bastide toma emprestado, num primeiro momento, um conceito do crítico de pintura Elie Faure - a transposição. Alguns pintores, ao representar a figura humana em recintos fechados (no interior dos

\footnotetext{
${ }^{3}$ A expressão é de Candido.
} 
ambientes), seriam capazes de tornar presente a natureza, pelo modo mesmo como trabalhavam o reflexo da luz e dos tons de uma natureza ausente (ou seja, fora da moldura e do foco do quadro) sobre a figura retratada. Assim, a "'transposição', conceito querido de Bastide, que o empregava com freqüência nos seus cursos de Sociologia da Arte" (CANDIDO, 2004b, p. 117), nos diz Candido, consiste, no primeiro âmbito em que foi empregado - a pintura - em "revestir os indivíduos das cores e nuanças da natureza que os cerca, em pôr o colorido das geleiras, as cintilações do mar, o castanho ou o ocre da terra natal sobre a pele e as roupas dos personagens". ${ }^{4}$

Tendo apresentado essa premissa, e transferindo-a para a literatura, Bastide propõe que em Machado de Assis o externo, ou, no caso que interessa a ele, a natureza, se incorpora não mais à superfície (pele ou roupa da figura), como na pintura, mas sim à própria construção, à própria fatura da personagem ou do enredo. Um dos exemplos de como isso acontece estaria no romance Quincas Borba. Lendo o livro, Bastide indaga o peso e lugar que tem ali a Natureza: "Sofia, para ver melhor o mar, não fecha os olhos, porque ele batia-lhe no pulso e as vagas lhe arrebentavam no coração? Sem dúvida, está na janela, mas se erguesse as pálpebras, a praia que veria não seria a verdadeira: a verdadeira praia, a sua, aquela na qual o barulho das ondas se confunde com o surdo ruído do coração, está dentro dela, e as águas a levam, sem vela nem remo" (BASTIDE, 2011 apud FREHSE; TITAN JR, 2011, p. 57-8).

Nessa mesma direção (nos termos de Bastide, a da presença alucinante de uma ausência), seria também possível citar a famosa caracterização de Capitu, cujos olhos "traziam não sei que fluido misterioso e enérgico, uma força que arrastava para dentro, como a vaga que se retira da praia, nos dias de ressaca. Para não ser arrastado [nos diz o narrador], agarrei-me às outras partes vizinhas, às orelhas, aos braços, aos cabelos espalhados pelos ombros; mas tão depressa buscava as pupilas, a onda que saía delas vinha crescendo, cava e escura, ameaçando envolver-me, puxar-me e tragar-me ${ }^{5}$. A metáfora, desenvolvida em função dos olhos de Capitu, se expande e alarga em um vulto de natureza (o mar e suas vagas), todo ele, no entanto, interno à personagem, e compondo-lhe o perfil e modo de ser. ${ }^{6}$

\footnotetext{
4 Bastide (que aqui resume a teoria de Faure) apud CANDIDO, 2004b, p. 117.

5 MACHADO DE ASSIS, Dom Casmurro, cap. XXXII apud BASTIDE, "Machado de Assis paisagista". In: Impressões do Brasil: Roger Bastide, ed. cit., p. 59.

6 Para compreender melhor o par ausência/presença, por meio do qual o professor francês lê o texto de Machado de Assis, e para sentir também a inclinação e estilo peculiares de seu ensaio (verificando ainda o amplo e variado alcance de seus interesses e leituras), seria interessante considerar o seguinte trecho, sobre o modo como a Natureza (ou aqui, mais especificamente, o mar) se infiltra na estrutura da prosa machadiana: “Em criança, Machado, interrogando o seu destino pela sorte da clara no copo d'água, via nos filamentos esbranquiçados a imagem de um navio partindo. E, embora homem de terra, sem aventuras, citadino agarrado às ruas cariocas, a predição se realizou. Como nas Naus Catarinetas do sertão, carregadas pelos homens sobre a terra dura e seca, como nas longínquas capelas do interior onde se balança, entre os ex-votos,
} 
A intuição crítica de Bastide, capaz de perceber o elemento externo na própria composição das personagens ou do enredo (além da Natureza, também a história recente do país e a vida nas cidades são estudadas em função da estrutura de contos e romances), fez que Antonio Candido julgasse "Machado de Assis paisagista" um "artigo capital" e "precursor, se levarmos em conta os hábitos críticos do momento em que foi publicado e, sobretudo, se pensarmos que o seu autor era sociólogo, e naquele tempo a sociologia podia ser uma presença tirânica e algo deformadora nos estudos literários" (CANDIDO, 2004b, p. 115). Assim, o artigo de Roger Bastide, de 1940, pode ser visto como um dos primeiros textos a contribuir para o posterior desenvolvimento de um método crítico, precisamente porque ali seu autor começou, mesmo que de modo ainda incipiente, o exercício difícil e apurado, diz Candido, de "dosar a sociologia em favor de uma crítica integrativa". ${ }^{7}$

O ensaio de Candido sobre Bastide pode ser lido portanto em várias frentes:

- como ocasião para pensar sobre o intenso interesse de uma primeira geração de professores franceses, na USP, pela realidade e pela literatura brasileiras;

- como testemunho do meio denso e fértil que caracterizou as primeiras trocas intelectuais, entre professores e alunos;

- como aclaramento da diferença entre nacionalismo e exotismo (apresentando pontos de contato com Mário de Andrade, como observa o próprio A. Candido);

- como notação dos primeiros passos promissores de leitura e análise da prosa machadiana, com características e premissas que, desenvolvidas pela próxima geração, culminam na proposição de uma crítica integrativa, em que história e sociedade podiam ser buscadas não como aspecto externo à literatura, mas internalizadas, coladas à fatura do texto.

No texto "Machado de Assis de outro modo", publicado 50 anos depois do artigo de Bastide ${ }^{8}$, Candido nos conta que o ensaio de seu

uma caravela branca, o complexo brasileiro do mar, de que tão bem falou Mário de Andrade, habitava no coração desse homem imóvel, mas cercado pelas águas em pleno Rio, e seus livros, como o copo da infância, encerram em filamentos dispersos a imagem alucinatório do Atlântico". "Machado de Assis paisagista". In: Impressões do Brasil: Roger Bastide, ed. cit., p. 61.

7 Trata-se aqui, como se percebe, de um Roger Bastide visto retrospectivamente, a partir do ângulo propiciado pelo método já plenamente desenvolvido de Candido, sem o qual o texto sobre Machado, de 1940, permaneceria provavelmente sem seguidores e sem repercussão. De todo modo, o diálogo entre professor e aluno, possibilitando a construção das premissas de uma leitura profícua do texto literário, pode ser visto como um dos pontos altos dessa "primeira idade universitária" (a expressão é de Gilda de Mello e Souza, no texto "A estética rica e a Estética pobre dos professores franceses", publicado em Exercícios de Leitura).

${ }^{8}$ Texto inicialmente publicado em II Colóquio UERJ - A interpretação. Rio de Janeiro: Imago, 1990. 
professor, "somado a outros do mesmo autor, bem como ao seu ensino e ao seu convívio, teve muita influência em mim, coisa que custei a perceber. Quando o reli há tempos, depois de muitos anos, senti que foi uma das fontes de várias ideias que estão na base da minha concepção de literatura brasileira. Os pontos de vista de Bastide se incrustaram de tal modo na minha mente, que perdi a noção do quanto lhe devo" (Idem, p. 115-6).

O depoimento delineia a formação de um método crítico, atravessando as gerações que se sucedem, na Universidade, mas é também, como se percebe, generoso, porque o salto entre a leitura que Bastide faz da internalização da Natureza, no texto sobre Machado de Assis, e a envergadura do método crítico de Antonio Candido, não é pequeno. Nesse processo, um esquema fecundo, mas ainda restrito, na leitura de Bastide (que estudava, como já visto, a presença pontual da Natureza em Machado de Assis) se amplia marcadamente (pelo recorte que lhe imprime Antonio Candido, movido também pelas ideias que tem a partir da leitura de muitos outros textos) em método de interpretação capaz de encontrar o dado externo (a história, a sociologia, a psicanálise ${ }^{9}$ ) como forma, como estrutura do texto. Com isso, propõe não uma crítica sociológica (como entenderam alguns), mas uma leitura voltada ao aspecto propriamente interno e constitutivo do texto literário, que é a sua forma. Assim, a comparação entre Candido e Bastide aponta - como se vê menos para um terreno de influências diretas, e mais para o modo como o olhar atento do aluno foi capaz de isolar, na crítica inventiva, mas ainda incipiente de seu professor, uma espécie de célula que poderia fermentar, propiciando o desenvolvimento de um método maduro e iluminador para a leitura do texto literário.

Se aqui nos detivemos na relação de Candido com Bastide, seria também possível, está claro, mencionar outros textos ou estudiosos cuja influência ou contato também contribuíram para o desenvolvimento da crítica de A. Candido. Como não é esse o intuito desta fala, cito apenas rápida e algo aleatoriamente dois exemplos possíveis, também porque foram lembrados nas falas de ontem: o conceito de poema enquanto organismo, de Cleanth Brooks; e a inclinação a uma crítica integrativa, também a partir do contraste com o método mais mecanicista de Silvio Romero.

De todo modo, e voltando ainda à relação de Candido com Bastide, talvez seja limitado afirmar que a única contribuição do sociólogo francês para o esquema interpretativo de Antonio Candido tenha sido o artigo sobre Machado de Assis. Se Candido aponta em Bastide a capacidade de trabalhar de modo profícuo com o difícil par literatura / sociologia, creio que um exemplo ainda a lembrar seria a crítica de Bastide a Castro Alves, que aqui comentamos, mais uma vez, a partir do olhar do próprio Candido

${ }_{9}^{9}$ Como diz ele em "Crítica e Sociologia". 
(porque é a sua leitura, interpretação e aproveitamento dos textos de seu professor o que interessa, nesta exposição).

De acordo com Candido (2004a), a leitura de Bastide teria ajudado a aclarar o alcance e significado das antíteses, em Castro Alves. ${ }^{10}$ Nos versos desse poeta, a antítese não seria mera figura poética, mas sim, "recurso de composição". "É certo [diz Candido] que Castro Alves a tomou de Victor Hugo. Posta, no entanto, a funcionar no Brasil, a antítese "assumiu outra dimensão, pois a sociedade local se caracterizava por certas grandes antíteses sociais, cuja existência" deu nova funcionalidade e peso à figura (p. 113). Num país às voltas com o contraste "Independência x Escravidão; Senhor branco x Escravo negro" (p. 113), a figura atingiria uma vertebração não encontrada na origem (ou seja, em V. Hugo). “Daí a possibilidade [diz Candido] de um funcionamento peculiar [da antítese], de significado diverso e sociologicamente muito mais relevante, que afasta a idéia de 'imitação mecânica'” (p. 113) e que torna local aquilo que seria, para um outro esquema crítico, um mero empréstimo ou importação feito a Vitor Hugo.

Comento apenas de passagem (por não ser o tema desta fala) que aqui se pode notar, igualmente, a relevância da ideia de Candido de que estudar literatura brasileira significa estudar também literatura comparada. Não para verificar uma suposta subordinação ao modelo, mas sim, como nesse exemplo, para compreender de que modo algo transposto de outro domínio (as antíteses de V. Hugo) passa a ter peso e relevância maiores - e mais expressivos - em solo brasileiro, em função justamente de um contexto específico e local. Aqui, são as iniquidades de um país (a escravidão e seus desdobramentos) o que impede que as antíteses de Castro Alves permaneçam mero objeto de composição ou estilo tomado a outro poeta, aparecendo antes, na composição, como elementos de fatura (e reveladoras de um contexto).

Dito isso, passo ao segundo momento desta fala, ou seja, aquele que buscará acompanhar a leitura que Candido, mobilizando a "combinação difícil" entre texto literário e carga de mundo nele sedimentada, faz do texto poético, ou, mais especificamente, de um trecho de um poema em

\footnotetext{
10 Veja-se a formulação de Candido sobre a construção das figuras (antíteses), por sua vez dependentes dos modos de apresentação do espaço, em "Navio Negreiro": "O que chama a atenção em primeiro lugar são os ângulos e as distâncias. $O$ observador que narra, postado idealmente na altura, vê ao longe um veleiro e ouve cantigas. Para saber o que é, pede figuradamente emprestadas as asas ao albatroz, (...) e chega perto. Agora está no meio dos movimentos e pode ver diretamente o horror da cena. /É portanto, através de perspectivas, distâncias e aproximações que o assunto é apresentado. Mas tão importantes quanto elas são o espaço e os elementos que o povoam: mar, céu, noite, lua, ondas, estrelas formam um quadro adequado ao titanismo da composição. Esses elementos emprestam uma dimensão enorme à cena e aos protagonistas, e seu efeito provém da maneira pela qual são usados como recursos de fatura, que parece baseada numa espécie de lei fundamental: o jogo de extremos, que se aproximam, se cruzam ou se repelem, criando grandes contrastes (...)" Cf. "Navio negreiro". In: Recortes, ed. cit., p. 55.
} 
prosa (ou de prosa poética, como querem alguns) que se encontra na abertura de A Idade do Serrote, de Murilo Mendes (cf. CANDIDO, 2004c). Cito o trecho:

O dia, a noite

Adão e Eva - complementares e adversativos.

Meus pais: Onofre e Elisa Valentina, Adão e Eva descendentes.

A multiplicação dos pais. A multiplicação dos peitos. A multiplicação dos pães. A multiplicação dos pianos ${ }^{11}$

O jardim-pomar da casa paterna, limite traçado ao meu incipiente saber. O sabor das frutas. A árvore da ciência do bem e do mal ao meu alcance. Um esboço de serpente pronta para armar o bote. Outros jardins pomares da casa de tias e primas

“O recurso principal de escrita [nesse texto, marcado acima em itálico] é a elipse, [diz Candido], que sugere a experiência fragmentária e desconexa da infância, condicionando uma realidade aproximativa e descontínua, que parece residir mais nas palavras do que nas coisas que elas designam" (CANDIDO, 2004c, p. 37) Podemos aventar, daí, a razão da primeira parte do título deste ensaio: mundo desfeito. $\mathrm{O}$ mundo da experiência racional foi corroído, esgarçado, "reduzido a impressões fugidias, incompletas, nascidas da percepção embrionária do menino pequeno. Mas a seguir, foi refeito pela palavra, tratada como se sobre ela, não sobre a realidade, repousasse o significado profundo" (Idem, p 37).

$\mathrm{O}$ crítico defende que a fragmentação do discurso, ao escamotear o vínculo ordenado dos elementos com a realidade, constrói, pela palavra, um outro mundo (aquele, justamente, em que impera o nexo ilógico, a elipse, o vínculo inesperado da expressão que tangencia o surrealismo etc.). Daí, num primeiro momento, o significado profundo se vincular não ao mundo externo (cuja organização foi desfeita), mas à palavra e sua carga de autonomia. O significado, diz Candido, invertendo a acepção corrente ou usual, repousaria sobre a palavra (o que significa dizer, aqui, sobre a estrutura em elipse, fragmentária), e não sobre o real.

Escutemos ainda Antonio Candido, sobre esse trecho de A Idade do serrote:

A mesma palavra (multiplicação) é repetida quatro vezes, multiplicando-se efetivamente, sempre ligada a outras irmanadas por uma homofonia feita de rimas quase toantes e entrelaçadas: pais-pães, peitos-pianos. É como se a palavra

${ }^{11}$ Grifo meu. 
propusesse um mundo refeito por ela, de tal modo que o discurso parece propor-se como finalidade de si mesmo, ao chamar a atenção sobre si por meio dos recursos de sonoridade e simbolização. (p. 37-8)

Assim, Antonio Candido aponta para a descostura da relação da palavra com seu referente externo (no mundo refeito pela palavra, no discurso que "parece propor-se como finalidade de si"). Mas a suposição de que o discurso seja a finalidade de si mesmo não é de fato o último passo e pode ser levada a outro nexo, mais produtivo, talvez. O próximo passo da leitura será buscar então, nesse trecho (que adquiriu relevo pelo trabalho de análise) um conteúdo sedimentado, a carga de mundo que se teria amalgamado àquela forma. Mas, como funcionaria então, precisamente, esse discurso, que ao mesmo tempo "garante e (...) perturba o nexo com o mundo"? (p. 38).

Continuemos a ler o Candido:

Aqui o mundo é o do nascimento, do aleitamento, das percepções iniciais. Mas para um católico como Murilo Mendes é também o senso do milagre (multiplicação dos pães, extensiva a outros níveis), que infunde transcendência ao quotidiano. E é senso de absurdo, exprimindo a nutrição espiritual através da arte, na proliferação surreal dos pianos, isto é, da sua sonoridade captada pelo menino (p. 38)

Se esse é o caso, e se se trata de buscar o aspecto que estaria plasmado na forma insólita, como se daria essa relação, aqui?

Talvez a articulação se deva a nexos de tipo associativo: o leite conduz ao pão (alimento), este é assimilado ao milagre da sua multiplicação por Jesus; o milagre por sua vez abre a possibilidade da multiplicação metonímica dos pianos. E assim vemos de que maneira um elemento ideológico, a religião, permite infletir o discurso no rumo do insólito.

O insólito, a "nutrição espiritual através da arte", o surrealismo, a proliferação absurda dos objetos (pianos) entram, no esquema que se torna nítido a partir da análise de Candido, não como tema, referência explícita, ou discurso explicativo, mas como forma, como arquitetura - a do fragmento, dos nexos existentes, mas insólitos, das sonoridades, homofonias etc. Daí, diz ainda Candido, ampliando muito o foco, resulta "o sentimento do quotidiano como milagre possível, idéia cara aos surrealistas e, por motivos em parte diferentes, a Murilo Mendes" (p. 38). Aqui, o crítico inverte a reflexão (antes voltada à possibilidade de que o discurso tivesse por sentido a si próprio) e passamos (seus leitores) a perceber a estrutura muito particular do texto de Murilo Mendes como forma que, pela impregnação ou sedimentação do externo (no exemplo 
dado, a ideia da multiplicação, que aqui une o "senso do milagre" ao "senso do absurdo") adquire aquela arquitetura específica. Nesse trecho do livro de Murilo Mendes (propõe Antonio Candido), as palavras que se desprendem do mundo, em sua estrutura fragmentária, lacunar, ilógica, acabam configurando a matéria que é, ela mesma, e paradoxalmente, uma espécie de sedimentação de um 'conteúdo de mundo': a religião. Ela surge aqui, no entanto, mais como um dispositivo por assim dizer estético (é inteiramente absorvida pela matéria mesma do discurso, pela estrutura da prosa lírica desse trecho de $A$ idade do serrote) que se abre então também, como visto, ao senso de absurdo.

Percebe-se, neste ponto do texto, aquilo que o próprio Candido já defendeu, com respeito às particularidades da crítica literária por ele exercida e de seus desdobramentos e alcance. $\mathrm{O}$ fato de que o método que propõe não é uma crítica sociológica, mas tão somente Crítica ${ }^{12}$. Porque a leitura de mundo que faz não se estende para fora, mas para dentro (para a forma, para a estrutura) do texto literário, lendo o mundo não no exterior, mas no mais íntimo da tessitura de poema, conto, romance.

É precisamente o estudo da articulação entre essas duas esferas (mundo e palavra, mundo e forma) o que está no cerne do desenvolvimento desse método crítico, que procurei comentar, a partir inicialmente de um dos muitos escritos (o texto de Bastide) que lhe deram inspiração e material a ser desenvolvido. Que esse primeiro ensaio, em 1940, tenha sido já sobre o funcionamento imanente do um aspecto do contexto (a Natureza), em Machado de Assis (ponto culminante da Formação da Literatura Brasileira), é algo que dá o que pensar. Mas, já tendo me estendido demais, termino aqui a minha fala.

${ }^{12}$ Cf. o ensaio "Crítica e sociologia". 


\section{Referências bibliográficas}

CANDIDO, Antonio. "Roger Bastide e a literatura brasileira”. In: Recortes. Rio de Janeiro: Ouro sobre azul, 2004a ( $3^{\mathrm{a}}$ ed.).

CANDIDO, Antonio. "Machado de Assis de outro modo". In: Recortes. Rio de Janeiro: Ouro sobre azul, 2004b ( $3^{\mathrm{a}}$ ed.).

CANDIDO, Antonio. "O Mundo desfeito e refeito". In: Recortes. Rio de Janeiro: Ouro sobre azul, 2004c ( $3^{\mathrm{a}}$ ed.)

BASTIDE, Roger. "Machado de Assis paisagista. In: Impressões do Brasil: Roger Bastide. Organização e prefácio Fraya Frehse e Samuel Titan Jr. São Paulo: Imprensa Oficial do Estado de São Paulo, 2011.

SOUZA, Gilda de Mello. "A estética rica e a estética pobre dos professores franceses". In: Exercícios de Leitura. São Paulo: Duas cidades, 1980.

PEIXOTO, Fernanda Arêas. "Os Brasis de Roger Bastide". In: BOTELHO, André; SCHWARCZ, Lilia Moritz (orgs.). Um enigma chamado Brasil. São Paulo: Companhia das letras, 2009, p. 187.

Betina Bischof é professora do Departamento de Teoria Literária e Literatura Comparada da Faculdade de Filosofia, Letras e Ciências Humanas da Universidade de São Paulo. É autora do livro Razão da recusa: um estudo da poesia de Carlos Drummond de Andrade (2005). Contato: bbischof@usp.br

ORCiD: https:/ / orcid.org/0000-0002-3362-742X 